\title{
Article
}

\section{Self-aldol condensation of aldehydes over Lewis acidic rare-earth cations stabilized by zeolites}

\author{
Tingting Yan a, Sikai Yao a, Weili Dai a,*, Guangjun Wu a , Naijia Guan a,b , Landong Li a,b,\# \\ a School of Materials Science and Engineering, Nankai University, Tianjin 300350, China \\ ${ }^{\mathrm{b}}$ Key Laboratory of Advanced Energy Materials Chemistry of the Ministry of Education, Nankai University, Tianjin 300071, China
}

\section{A R T I C L E I N F O}

\section{Article history:}

Received 17 May 2020

Accepted 28 June 2020

Available online 5 September 2020

\section{Keywords:}

Self-aldol condensation

Aldehyde

Rare-earth cations

Zeolite

Lewis acid

\begin{abstract}
A B S T R A C T
The self-aldol condensation of aldehydes was investigated with rare-earth cations stabilized by [Si]Beta zeolites in parallel with bulk rare-earth metal oxides. Good catalytic performance was achieved with all Lewis acidic rare-earth cations stabilized by zeolites and yttrium appeared to be the best metal choice. According to the results of several complementary techniques, i.e., temperature-programmed surface reactions, in situ diffuse reflectance infrared Fourier transform spectroscopy, ultraviolet-visible diffuse reflectance spectroscopy, the reaction pathway and mechanism of the aldehyde self-aldol condensation over Y/Beta catalyst were studied in more detail. Density functional theory calculations revealed that aldol dehydration was the rate-limiting step. The hydroxyl group at the open yttrium site played an important role in stabilizing the transition state of the aldol dimer reducing the energy barrier for its hydration. Lewis acidic $\mathrm{Y}(\mathrm{OSi})(\mathrm{OH})_{2}$ stabilized by zeolites in open configurations were identified as the preferred active sites for the self-aldol condensation of aldehydes.
\end{abstract}

(C) 2021, Dalian Institute of Chemical Physics, Chinese Academy of Sciences. Published by Elsevier B.V. All rights reserved.

\section{Introduction}

The aldol condensation is a key carbon-carbon (C-C) coupling reaction to manufacture many specialty chemicals and commodities. It attracted tremendous interest in bio-oil upgrading and biomass conversion as it provides an attractive route to elongate carbon chains and decrease the $0 / C$ ratios [1-9]. Traditionally, the aldol condensation reaction is catalyzed by homogenous base catalysts such as sodium and calcium hydroxides, but a significant amount of waste water is generated and further purification is required, causing an additional disposal cost [10]. Consequently, the development of solid catalysts to decrease the production cost, promote a clean manufacture, and simplify the process, is necessary.

Recently, a variety of solid acids and bases were studied for the aldol condensation. For example, metal oxides and zeolites are used as solid acids, while hydroxyapatites, hydrotalcites and alkaline-earth or rare-earth metal oxides, e.g., $\mathrm{CaO}, \mathrm{MgO}$, $\mathrm{La}_{2} \mathrm{O}_{3}$ and $\mathrm{Y}_{2} \mathrm{O}_{3}$, are used as solid bases [11-18]. Although an acceptable aldol condensation activity was achieved with these catalysts, catalyst deactivation occurs rapidly, especially in the presence of bio-based acids like acetic acid [19-22]. Lewis acidic heteroatom substituted zeolites, including Sn-Beta, Ti-Beta, Zr-Beta and Ta-Beta, were recently developed for this reaction [15,16,23-29]. It was reported that two types of framework heteroatoms might exist, the so-called closed and

\footnotetext{
* Corresponding author. Tel/Fax: +86-22-85358536; E-mail: weilidai@nankai.edu.cn

\# Corresponding author. Tel/Fax: +86-22-23500341; E-mail: lild@nankai.edu.cn

This work is supported by the National Natural Science Foundation of China (21872072), the Municipal Natural Science Foundation of Tianjin (18JCZDJC37400, 18JCJQJC47400), and SINOPEC (419040).

DOI: 10.1016/S1872-2067(20)63675-0 | http://www.sciencedirect.com/science/journal/18722067 | Chin. J. Catal., Vol. 42 , No. 4, April 2021
} 
open sites [30-33]. The closed sites represent transition metal (M) ions fully connected to the zeolite framework with exclusive Si-O-M linkages, while open sites correspond to partially hydrolyzed $\mathrm{M}$ sites with at least one $\mathrm{M}-\mathrm{OH}$ group. In comparison with the closed sites, the Lewis acidic open sites generally exhibit better catalytic performance [34]. Our recent work demonstrated that the Lewis acidic yttrium species stabilized by siliceous Beta zeolite, i.e. Y/Beta, exhibited distinct characteristics in the aldol condensation [35,36]. The confinement effect of zeolites could effectively increase the chance of reagent and intermediates to react with each other on the functional sites to generate the target product rather than escape from the pores. However, the reaction pathway and the nature of the working Lewis acidic sites, i.e. the open sites or closed sites in Y/Beta, are still not clear.

In the present study, several types of rare-earth cations stabilized by [Si]Beta zeolites were prepared in parallel with bulk rare-earth metal oxides via post-synthesis modifications and applied in the self-condensation of aldehydes. The effects of rare-earth cations and supports on the catalytic performance were investigated. In situ diffuse reflectance infrared Fourier transform spectroscopy (DRIFTS), ultraviolet-visible diffuse reflectance spectroscopy (UV-vis DRS), and temperature-programmed surface reactions (TPSR) were applied to simultaneously monitor dynamic changes on the catalyst surface and the product distribution in the gas phase. Finally, the nature of the working Lewis acidic sites and the detailed reaction mechanism of the aldehyde self-condensation were clarified via first-principle periodic density functional theory (DFT) calculations.

\section{Experimental}

\subsection{Catalyst preparations}

Scandium nitrate ( $>99 \%$ ), yttrium nitrate ( $>99 \%$ ), lanthanum nitrate ( $>99 \%$ ), cerium nitrate ( $>99 \%$ ), scandium oxide ( $>99 \%$ ), yttrium oxide ( $>99 \%$ ), lanthanum oxide ( $>$ 99\%), and cerium oxide ( $>99 \%$ ) were purchased from Alfa Aesar and used as received without further purification.

Rare-earth cations stabilized by BEA zeolites were prepared via a two-step metalation procedure described elsewhere [34-37]. Typically, the commercial H-Beta zeolite (Sinopec. Co.) with a nominal $n_{\mathrm{Si}} / n_{\mathrm{Al}}$ ratio of 14 was dealuminated by reflux in $\mathrm{HNO}_{3}$ aqueous solution ( $\left.13 \mathrm{~mol} / \mathrm{L}, 20 \mathrm{~mL} / \mathrm{g}_{\text {zeolite }}\right)$ under stirring at $373 \mathrm{~K}$ for $20 \mathrm{~h}$ to produce a fully dealuminated [Si]Beta zeolite. The slurry was filtered, washed thoroughly with deionized water, dried at $373 \mathrm{~K}$ overnight and further calcined at $823 \mathrm{~K}$ for $6 \mathrm{~h}$ (heating rate at $5 \mathrm{~K} / \mathrm{min}$ ). Then, rare-earth cations stabilized by [Si]Beta zeolite were prepared by grinding an appropriate amount of [Si]Beta with the corresponding metal nitrates to form an intimate mixture. The solids were treated by calcination in flowing air at $823 \mathrm{~K}$ for $6 \mathrm{~h}$ to derive the final products with similar weight loadings of $\sim 5 \%$. The as-obtained samples were directly utilized as catalysts in the self-aldol condensation of aldehydes.

For reference, $5 \% \mathrm{Y} / \mathrm{SiO}_{2}$ was prepared by dry impregnation of an yttrium nitrate precursor onto the $\mathrm{SiO}_{2}$ support, followed by calcination in flowing air at $823 \mathrm{~K}$ for $6 \mathrm{~h}$.

\subsection{Structural characterizations}

The X-ray diffraction (XRD) patterns were recorded on a Rigaku SmartLab powder diffractometer using $\mathrm{Cu} K_{\alpha}$ radiation $(\lambda=0.1542 \mathrm{~nm})$ with a scanning speed of $4^{\circ} / \mathrm{min}$ in the region of $5^{\circ}-50^{\circ}$.

The surface areas and pore volumes of the calcined samples were measured by means of argon adsorption/desorption on a Quantachrome iQ-MP gas adsorption analyzer at $87 \mathrm{~K}$. Before the argon adsorption, catalysts were dehydrated at $573 \mathrm{~K}$ for 6 h. The total surface area was calculated via the Brunauer-Emmett-Teller (BET) equation and the micropore size distribution was determined by the t-plot method.

The chemical compositions of the catalysts were measured by inductively coupled plasma atomic emission spectrometry (ICP-AES) on a Thermo IRIS Intrepid II XSP atomic emission spectrometer.

DRIFTS of samples were recorded on a Bruker Tensor 27 spectrometer with 128 scans at a resolution of $2 \mathrm{~cm}^{-1}$. Self-supporting sample pellets were placed in the reaction chamber and pretreated in flowing dry air at $673 \mathrm{~K}$ for $1 \mathrm{~h}$.

The solid-state magic angle spinning nuclear magnetic resonance (MAS NMR) measurements were conducted on a Bruker Avance III spectrometer at resonance frequencies of 100.6 MHz for ${ }^{13} \mathrm{C}$ nuclei. Acetone- $2-{ }^{13} \mathrm{C}\left(99.5 \%{ }^{13} \mathrm{C}\right.$-enriched, Sigma Aldrich) was utilized as a probe to investigate the surface acid sites of the as-prepared samples. ${ }^{13} \mathrm{C}$ MAS NMR spectra were recorded applying cross-polarization (CP) with a contact pulse of $4 \mathrm{~ms}$ and a repetition time of $4 \mathrm{~s}$. All the ${ }^{13} \mathrm{C}$ MAS NMR studies were performed with dehydrated samples, which were treated at $723 \mathrm{~K}$ in vacuum (below $10^{-2} \mathrm{~Pa}$ ) for $12 \mathrm{~h}$. Thereafter, acetone-2-13C probe molecules were loaded for further studies as described elsewhere [38].

\subsection{Catalytic reactions}

The self-aldol condensation of acetaldehyde and propyl aldehyde was performed in a fixed-bed reactor at atmospheric pressure. Typically, $0.16 \mathrm{~g}$ of the as-prepared catalyst (sieve fraction, $0.25-0.5 \mathrm{~mm}$ ) was placed in a quartz reactor (5 $\mathrm{mm}$ i.d.) and pretreated in flowing nitrogen $(20 \mathrm{~mL} / \mathrm{min})$ at $673 \mathrm{~K}$ for $1 \mathrm{~h}$. After cooled to the desired temperature of $573 \mathrm{~K}$, liquid aldehyde was injected into the system using a Shimadzu LC-20AT dual reciprocating plunger HPLC pump at a rate of 0.2 $\mathrm{mL} / \mathrm{h}$ under nitrogen flow $(20 \mathrm{~mL} / \mathrm{min})$, corresponding to the weight hourly space velocity (WHSV) of $1.0 / \mathrm{h}$. The products were analyzed online by a Shimadzu GC-2010 plus chromatograph with flame ionization detector (FID) equipped with a Poraplot Q-HT column $(40 \mathrm{~m} \times 0.18 \mathrm{~mm} \times 0.18 \mu \mathrm{m})$. The gaseous products $\left(\mathrm{H}_{2}, \mathrm{CO}\right.$ and $\left.\mathrm{CO}_{2}\right)$ were online monitored with a mass spectrometer (Pfeiffer Omnistar GSD 320).

The aldehyde conversion and the product selectivity (for example 2-methyl-2-pentenal) are defined as follows: 
aldehyde co nversion $(\operatorname{mol} \%)=\frac{[\text { aldehyde }]_{\text {inlet }}-[\text { aldehyde }]_{\text {outlet }}}{[\text { aldehyde }]_{\text {inlet }}} \times 100 \%$

2-methyl-2-pentenal selectivity $(\mathrm{mol} \%)=\frac{2 \times[2 \text {-methyl-2-pentenal }]_{\text {outlet }}}{[\text { aldehyde }]_{\text {inlet }}-[\text { aldehyde }]_{\text {outlet }}} \times 100 \%$

\subsection{TPSR}

TPSR were performed in the same fixed-bed reactor (ut supra) connected to a downstream gas sampling mass spectrometer. Helium was utilized as the carrier gas since its lower $m / z$ value of 4 has no overlap with the main products or intermediates.

For propyl aldehyde TPSR, $0.16 \mathrm{~g}$ of catalyst was pretreated by heating to $723 \mathrm{~K}$ and kept for $1 \mathrm{~h}$ under He flow (20 $\mathrm{mL} / \mathrm{min}$ ) to desorb all water and other impurities adsorbed on the surface. After cooling to $298 \mathrm{~K}$, propyl aldehyde was continually introduced to the system and the experiment performed in the temperature range of 298-723 $\mathrm{K}$ by heating at the rate of $5 \mathrm{~K} / \mathrm{min}$. To obtain more information about the variety of products and intermediates in propyl aldehyde conversion, TPSR profiles were realized by monitoring the mass-to-charge signals of $18,58,41$ and 116 using the mass spectrometer corresponding to the partial pressure of water, propyl aldehyde, 2-methyl-2-pentenal and 3-hydroxyl-2methylpentanal, respectively (see Table S1 for details).

\subsection{In situ DRIFTS}

The surface intermediates formed during the self-aldol condensation of propyl aldehyde were investigated by in situ DRIFTS, as described elsewhere [36]. The DRIFT spectra were recorded on a Bruker Tensor 27 spectrometer equipped with an in situ reaction chamber and a liquid $\mathrm{N}_{2}$ cooled high sensitivity mercury-cadmium-telluride (MCT) detector. Prior to the FTIR studies, ca. $20 \mathrm{mg}$ of catalysts were finely ground and placed into the chamber. Then, the catalysts were pretreated by heating to $673 \mathrm{~K}$ for $1 \mathrm{~h}$ in flowing argon $(10 \mathrm{~mL} / \mathrm{min})$ with the intent to remove any residual water and other volatiles that may have adsorbed during catalyst storage. Then the temperature was decreased to $573 \mathrm{~K}$ to collect the background spectra. After importing the background spectra, the propyl aldehyde was introduced into the chamber with a WHSV $=1.0 / \mathrm{h}$ and time-resolved spectra were recorded with a resolution of 4 $\mathrm{cm}^{-1}$ and an accumulation of 128 scans.

\subsection{In situ UV-vis DRS}

The nature of reaction intermediates formed on the catalyst during the self-aldol condensation was monitored by a PerkinElmer Lambda 750 UV/VIS/NIR spectrometer equipped with an in situ reaction chamber. The UV-vis DRS were recorded in a scan drive mode in the range of 200-600 $\mathrm{nm}$. Prior to the recording of time-dependent spectra, ca. $20 \mathrm{mg}$ of catalyst was placed in the chamber and activated at $723 \mathrm{~K}$ for $1 \mathrm{~h}$ in flowing argon $(20 \mathrm{~mL} / \mathrm{min})$. Then, a reference spectrum was recorded on a fresh sample placed inside the reaction chamber. The propyl aldehyde was introduced into the chamber at a WHSV = $1.0 / \mathrm{h}$.

\subsection{DFT calculations}

DFT calculations were performed with the Vienna ab-initio simulation package (VASP) $[39,40]$ using the projector augmented wave method (PAW) [41]. The PerdewBurke-Ernzerhof (PBE) generalized-gradient-approximation (GGA) exchange-correlation functional was used with a kinetic cutoff energy of $400 \mathrm{eV}$ [42]. Brillouin-zone integrations were performed using the gamma point [43]. All self-consistent field (SCF) calculations were converged to $1 \times 10^{-4} \mathrm{eV}$ and the forces on the atoms which were allowed to relax were $<0.03 \mathrm{eV} \AA^{-1}$. The calculations employed the Bayesian error estimation functional with van der Waals correlation (BEEF-vdW) [44]. Transition state searches were done using the dimer $[45,46]$ methods implemented in the VASP transitions state theory (VTST) tool for (VASP).

\section{Result and discussion}

\subsection{Performance of the as-prepared catalysts}

The catalytic performance of rare-earth cations stabilized by zeolites and that of rare-earth metal oxides was initially investigated with the self-aldol condensation of propyl aldehyde (Fig. 1). Notably, less than 2\% propyl aldehyde conversion with a 2-methyl-2-pentenal selectivity of $70 \%-90 \%$ was obtained over the basic bulk rare-earth metal oxides. The low selectivity to the target product is due to the presence of unconverted intermediate 3-hydroxy-2-methylpentanal and the formation of some large oligomers (see Table S2 for details). A propyl aldehyde conversion of $3 \%$ with a high 2-methyl-2-pentenal selectivity of $95 \%$ was achieved over [Si]Beta, indicating that the weak acidic $\mathrm{Si}-\mathrm{OH}$ groups could catalyze the reaction but with very low activity. After the introduction of rare-metal cations, i.e. rare-metal cations stabilized by zeolite, a great improvement in the catalytic activity with more than $30 \%$ propyl aldehyde conversion was observed. Among all the catalysts inves-

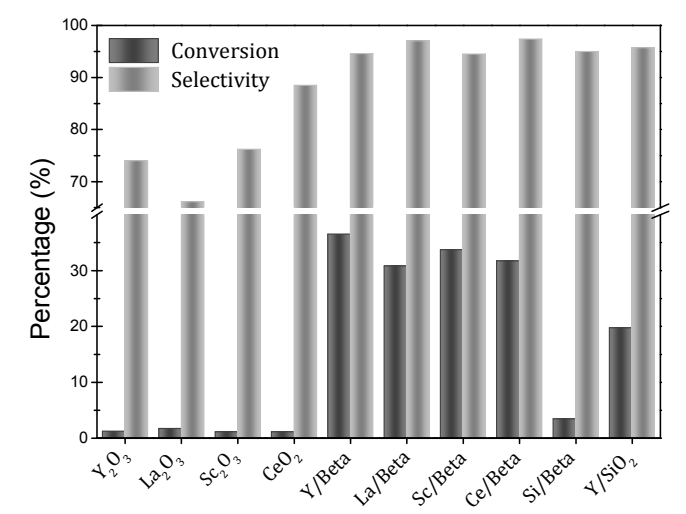

Fig. 1. Self-aldol condensation of propyl aldehyde over different catalysts. Reaction conditions: 0.16 g catalyst, WHSV $=1.0 / \mathrm{h}, T=573 \mathrm{~K}$, TOS $=2 \mathrm{~h}$. 
tigated, Y/Beta showed a slight advantage in terms of propyl aldehyde conversion and 2-methyl-2-pentenal selectivity. In order to get an in-depth understanding on the structural effect of the supports, the catalytic performance of yttrium supported on amorphous $\mathrm{SiO}_{2}$ was also tested for comparison. Although, a high 2-methyl-2-pentenal selectivity of 95\% was achieved over $\mathrm{Y} / \mathrm{SiO}_{2}$, the propyl aldehyde conversion was about $50 \%$ lower than that of Y/Beta. This could be due to the structural zeolite confinement effect [35]. That is, propyl aldehyde experienced a diffusion resistance within the zeolite channels, and thus the activated propyl aldehyde had a higher chance to react with another propyl aldehyde in the gas phase rather than escape from the pores, corresponding to a higher propyl aldehyde conversion. Therefore, the combination and interplay between rare-earth cations and [Si]Beta zeolite support plays a pivotal role in the self-aldol condensation of propyl aldehyde. The self-aldol condensation of acetaldehyde was also investigated with rare-earth cations stabilized by zeolites and bulk rare-earth oxides, and similar trends were observed (Fig. S1). However, the handling of acetaldehyde requires extra care due to its low boiling point of $293 \mathrm{~K}$.

Fig. 2 depicts the time-on-stream (TOS) characteristics of propyl aldehyde conversion and product selectivity with respect to various rare-earth cations stabilized by zeolite. Similar trends of propyl aldehyde conversion and product selectivity were observed for all samples within the TOS of $3 \mathrm{~h}$. Typically, a stable 2-methyl-2-pentenal selectivity of about 95\% was observed with TOS, but the propyl aldehyde conversion gradually decreased from $40 \%$ to $34 \%$ over Y/Beta. The catalytic performance of spent Y/Beta could be fully recovered through simple calcination regeneration, indicating that carbon deposits were responsible for the catalyst deactivation, as confirmed by thermogravimetric analysis presented in Fig. S2. According to previous studies, the organic deposits might be long-chain condensation products, or bulky aromatics originating from cyclic trimers of the sequential propyl aldehyde self-condensation [47-50].

\subsection{Physicochemical properties of catalysts}

For a better understanding of the textural properties of the

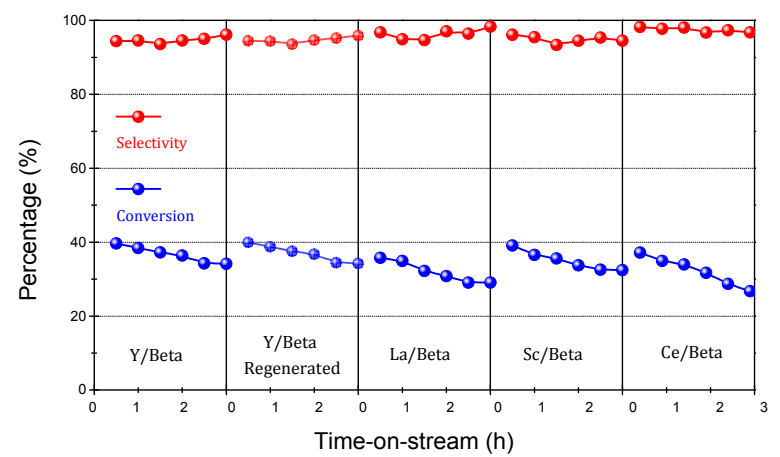

Fig. 2. Propyl aldehyde conversion with time-on-stream of $\mathrm{Y} /$ Beta, La/Beta, Sc/Beta and Ce/Beta catalysts. Reaction conditions: $0.16 \mathrm{~g}$ catalyst, $\mathrm{WHSV}=1.0 / \mathrm{h}, T=573 \mathrm{~K}$; Regeneration conditions: calcination in flowing air at $773 \mathrm{~K}$ for $4 \mathrm{~h}$. catalysts, the possible structure changes of Beta zeolites after the two-step metalation procedures were investigated by XRD and the corresponding patterns are shown in Fig. S3. Typical diffraction lines characteristic of the BEA topology were observed for all samples, indicating that the BEA structure was well preserved after dealumination and rare-earth cation introduction, in line with previous reports [47-49]. No other diffraction lines due to rare-earth metal oxides occurred, suggesting that the rare-earth cations were highly dispersed within the [Si]Beta matrix. The well-preserved microporous BEA structure after dealumination and rare-earth cation introduction was further confirmed by argon physisorption (Fig. S4). All modified samples exhibited the same type I isotherms similar to that of the parent H-Beta zeolite. The surface areas and micropore volumes are summarized in Table 1. Similar BET surface areas (524-581 $\mathrm{m}^{2} / \mathrm{g}$ ) but slightly different micropore volumes $\left(0.170-0.206 \mathrm{~cm}^{3} / \mathrm{g}\right)$ were observed for all samples, which again confirmed that the textural properties of Beta zeolites were unchanged after dealumination and rare-earth cation incorporation.

According to our previous work, the dealumination of H-Beta and incorporation of metal heteroatoms were associated with the evolution of silanol groups related to the vacant sites during post-synthesis [47-49]. As shown in Fig. 3, the parent H-Beta exhibited two major bands at 3730 and 3600 $\mathrm{cm}^{-1}$, corresponding to isolated terminal silanol $\mathrm{Si}-\mathrm{OH}$ and bridging hydroxyl group $\mathrm{Si}-\mathrm{OH}-\mathrm{Al}$, respectively. Meanwhile, the very weak bands at 3774 and $3655 \mathrm{~cm}^{-1}$ were assigned to extra framework $\mathrm{Al}-\mathrm{OH}$ [50]. After treating in nitric acid, the above three bands associated with $\mathrm{Al}$ species disappeared due to the complete elimination of $\mathrm{Al}$ from the framework, in agreement with ICP analysis ( $\mathrm{Si} / \mathrm{Al}>1800)$. In addition, the intensities of the 3730 and $3525 \mathrm{~cm}^{-1}$ band, corresponding to isolated internal $\mathrm{Si}-\mathrm{OH}$ at framework defects and hydrogen-bonded silanol groups for [Si]Beta, increased, indicating the creation of silanol nests from dealumination [51,52]. The intensities of $\mathrm{Si}-\mathrm{OH}$ bands at 3730 and $3525 \mathrm{~cm}^{-1}$ decreased after the introduction of rare-earth cations, indicating the interaction between the rare-metal cations and the silanol groups.

To understand the surface sites of the rare-earth cations stabilized by zeolites, acetone-2-13C was utilized as a probe molecule and the ${ }^{13} \mathrm{C}$ CPMAS NMR spectra of the dehydrated samples after acetone-2-13C loading are shown in Fig. 4. A dominant signal at $\delta_{13 \mathrm{C}}=208 \mathrm{ppm}$ due to physisorbed ace-

Table 1

Physicochemical properties of zeolites.

\begin{tabular}{lccc}
\hline Catalyst & $n_{\mathrm{si}} / n_{\mathrm{Al}}{ }^{\mathrm{a}}$ & $\begin{array}{c}\text { Surface area }{ }^{\mathrm{b}} \\
\left(\mathrm{m}^{2} / \mathrm{g}\right)\end{array}$ & $\begin{array}{c}\text { Pore volume }^{\mathrm{c}} \\
\left(\mathrm{cm}^{3} / \mathrm{g}\right)\end{array}$ \\
\hline H-Beta & 14 & 562 & 0.194 \\
[Si]Beta & $>1800$ & 581 & 0.206 \\
Y/Beta & $>1800$ & 527 & 0.171 \\
La/Beta & $>1800$ & 524 & 0.170 \\
Ce/Beta & $>1800$ & 532 & 0.174 \\
Sc/Beta & $>1800$ & 531 & 0.172 \\
\hline
\end{tabular}

a Determined by ICP; ${ }^{\mathrm{b} C a l c u l a t e d}$ by the BET method; ${ }^{\mathrm{c} C a l c u l a t e d}$ from $t$-plot method. 


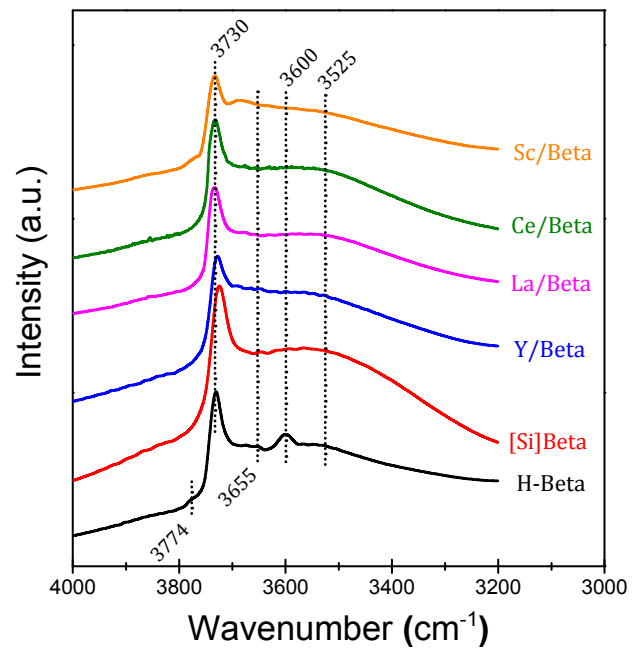

Fig. 3. DRIFTS in the hydroxyl regions of selected zeolite samples.

tone-2-13C at nonacidic silanol groups occurred for all samples the signal at $\delta_{13 \mathrm{C}}=30 \mathrm{ppm}$ corresponds to the non-13C-enriched methyl groups). After the introduction of rare-earth cations a new signal appeared at $\delta_{13 \mathrm{c}}=225 \mathrm{ppm}$ which is related to medium Lewis acid sites [36]. The medium Lewis acid sites originate from the rare-earth $\mathrm{M}$ sites connected to the framework of [Si]Beta via Si-O-M linkages. Furthermore, signals at $73,101,125,158$ and 171 ppm occurred due to the self-aldol condensation of acetone molecules catalyzed by Lewis acid sites [38]. The higher intensities of these signals with respect to Y/Beta and Sc/Beta indicated their higher self-aldol

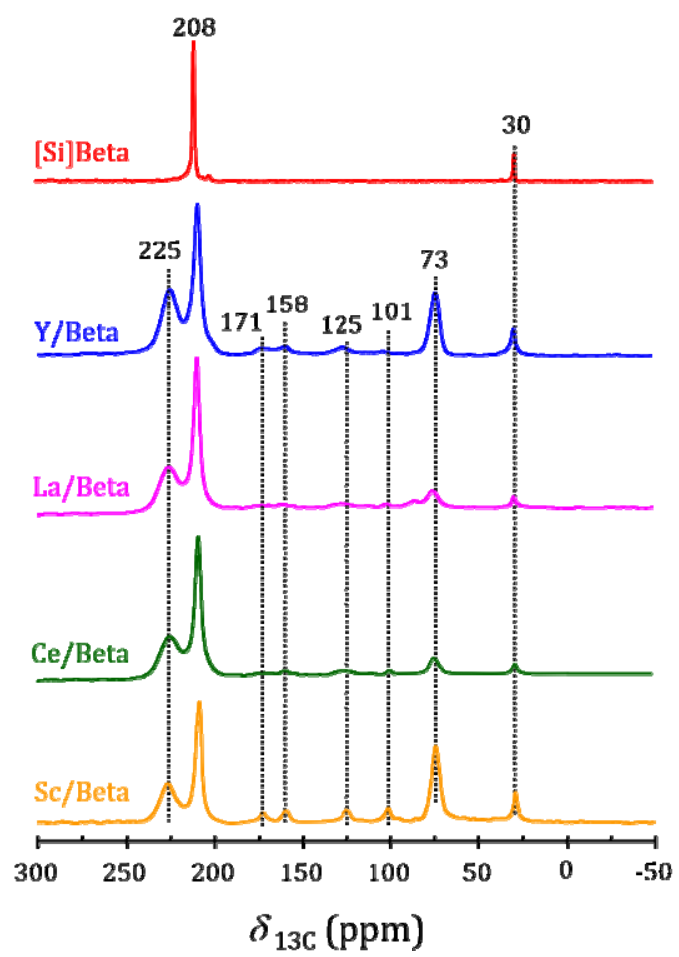

Fig. 4. ${ }^{13} \mathrm{C}$ CPMAS NMR spectra of zeolite samples after acetone-2-13C adsorption. condensation activity in comparison with La/Beta and Ce/Beta, in line with the catalytic results (Fig. 1).

Summarizing the above-mentioned characterization results, we conclude that the textural properties of Beta zeolites were well preserved after dealumination and rare-earth cation incorporation. In addition, the introduction of rare-earth cations into [Si]Beta zeolite produced similar Lewis acid sites, while yttrium and scandium exhibited higher self-aldol condensation activity in comparison with lanthanum and cerium.

\subsection{In situ DRIFTS of propyl aldehyde condensation over Y/Beta}

According to the catalytic performance and the physicochemical properties of the as-prepared rare-earth cations stabilized by zeolites, the Lewis acidic Y/Beta appeared to be most active in the propyl aldehyde condensation. To obtain information about the organic intermediates formed during propyl aldehyde condensation, time-resolved in situ DRIFTS were recorded over Lewis acidic $\mathrm{Y} /$ Beta and the basic $\mathrm{Y}_{2} \mathrm{O}_{3}$ for comparison (Fig. 5). Negative bands at high wavenumbers of 3734 and $3672 \mathrm{~cm}^{-1}$ due to the interaction of propyl aldehyde with surface $\mathrm{OH}$ groups, i.e. $\mathrm{Si}-\mathrm{OH}$ and $\mathrm{Y}-\mathrm{OH}$ groups [36], respectively, occurred on Y/Beta. Additionally, the earlier occurrence of the negative band at $3672 \mathrm{~cm}^{-1}$ indicated that propyl aldehyde preferentially occupied the $\mathrm{Y}-\mathrm{OH}$ sites. Bands in the range of 2966-2717 $\mathrm{cm}^{-1}$, assigned to aliphatic C-H stretching vibrations of propyl aldehyde, were observed on both Y/Beta and $\mathrm{Y}_{2} \mathrm{O}_{3}$ samples [53]. However, significant differences were observed for the $\mathrm{Y} /$ Beta and $\mathrm{Y}_{2} \mathrm{O}_{3}$ catalysts in the region of $1760-1000 \mathrm{~cm}^{-1}$. Clear bands at 1695 and $1643 \mathrm{~cm}^{-1}$ assigned to the $\alpha, \beta$-unsaturated compound, i.e. the condensation product

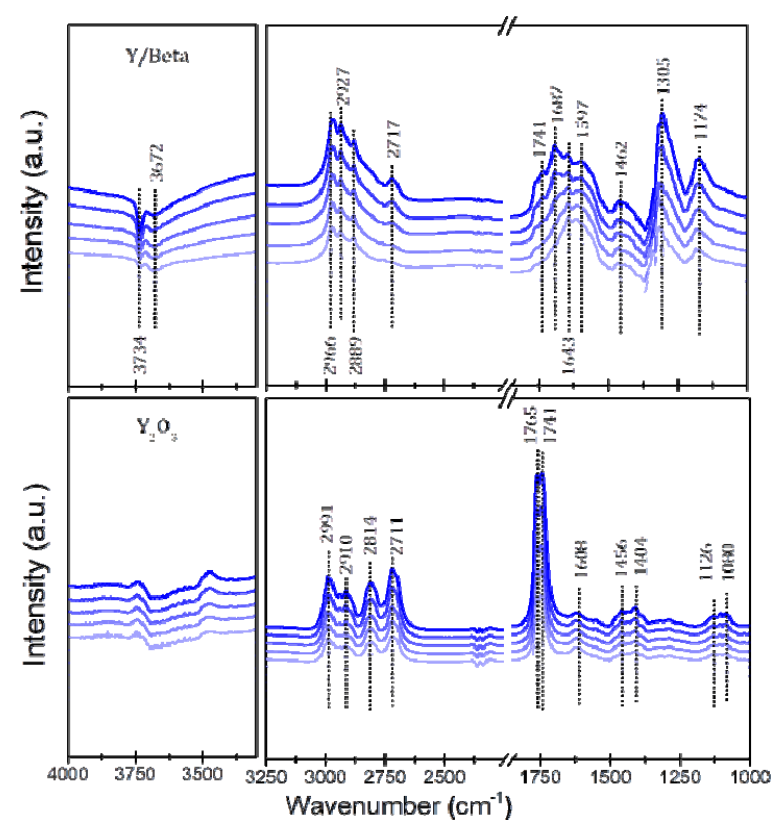

Fig. 5. In situ DRIFTS recorded during propyl aldehyde conversion over $\mathrm{Y} /$ Beta and $\mathrm{Y}_{2} \mathrm{O}_{3}$ for TOS of $60 \mathrm{~min}$. Reaction conditions: WHSV = 1.0/h, $T=573 \mathrm{~K}$. 
Table 2

Summary of IR bands observed and their assignments.

\begin{tabular}{lc}
\hline IR bands & Assignments \\
\hline $3734 \mathrm{~cm}^{-1}$ & O-H stretching vibrations of Si-OH \\
$3672 \mathrm{~cm}^{-1}$ & O-H stretching vibrations of Y-OH \\
$3000-2700 \mathrm{~cm}^{-1}$ & C-H stretching vibrations of methyl and methylene groups \\
$1741 \mathrm{~cm}^{-1}$ & $\mathrm{C}=0$ stretching vibrations of chemisorbed aldehydes \\
$1765 \mathrm{~cm}^{-1}$ & $\mathrm{C}=0$ stretching vibrations of gas phase aldehydes \\
$1687 \mathrm{~cm}^{-1}$ & $\mathrm{C}=0$ stretching vibrations of $\alpha, \beta$-unsaturated carbonyl groups \\
$1643 \mathrm{~cm}^{-1}$ & $\mathrm{C}=\mathrm{C}$ stretching vibrations of $\alpha, \beta$-unsaturated carbonyl groups \\
$1608 \& 1597 \mathrm{~cm}^{-1}$ & $\mathrm{C}=\mathrm{C}$ stretching vibrations of carbonaceous or aromatics species \\
$1462 \mathrm{~cm}^{-1}$ & C-H bending vibrations of aromatic ring \\
$1456 \& 1404 \mathrm{~cm}^{-1}$ & $\mathrm{C}-\mathrm{H}$ bending vibrations of aldehyde or aldol dimer \\
$1305 \& 1174 \mathrm{~cm}^{-1}$ & Aldehyde molecules coordinated to Lewis acid sites
\end{tabular}

2-methyl-2-pentenal, immediately appeared regarding Y/Beta, indicating the rapid condensation of propyl aldehyde. This assignment was confirmed by the adsorption of 2-methyl-2-pentenal on Y/Beta at room temperature, which resulted in two bands at 1695 and $1645 \mathrm{~cm}^{-1}$ (Fig. S5). With progressing propyl aldehyde conversion, weak adsorption bands at 1741 and $1462 \mathrm{~cm}^{-1}$ started to appear. The former is attributed to the $\mathrm{C}=0$ stretching band of propyl aldehyde [54], as supported by the occurrence of the $1740 \mathrm{~cm}^{-1}$ band upon pure propyl aldehyde adsorption on $\mathrm{Y} /$ Beta at room temperature (Fig. S6). The latter band is ascribed to the $\mathrm{C}-\mathrm{H}$ bending vibrations of propyl aldehyde or the aldol dimer product [53]. With the further progress in propyl aldehyde conversion, a broad band at $1597 \mathrm{~cm}^{-1}$ appeared. This band along with the broad band at $1462 \mathrm{~cm}^{-1}$ was attributed to $\mathrm{C}=\mathrm{C}$ ring vibrations of aromatics or large coke compounds, such as mesitylene, 2,4,6-trimethylphenol, which originated from the cyclic trimers of propyl aldehyde $[55,56]$. In addition, strong bands at the low wavenumbers of 1305 and $1174 \mathrm{~cm}^{-1}$ were related to propyl aldehyde molecules coordinated to Lewis acid sites of Y/Beta, revealing the interaction between propyl aldehyde molecules and the Lewis acidic yttrium sites [36].

In contrast, two strong bands at 1765 and $1741 \mathrm{~cm}^{-1}$ due to $\mathrm{C}=\mathrm{O}$ stretching vibrations of gas phase and chemisorbed propyl aldehyde, respectively, rapidly appeared for $\mathrm{Y}_{2} \mathrm{O}_{3}$ after feeding propyl aldehyde, which were considerably stable with increasing propyl aldehyde conversion. In addition, two weak bands at 1456 and $1404 \mathrm{~cm}^{-1}$ corresponding to $\mathrm{C}-\mathrm{H}$ bending vibrations of propyl aldehyde and the aldol dimer product [53,57], occurred for $\mathrm{Y}_{2} \mathrm{O}_{3}$. These results indicated that a very low propyl aldehyde conversion occurred over $\mathrm{Y}_{2} \mathrm{O}_{3}$ (the reaction stopped at the aldol dimer formation), in good agreement with the catalytic results presented in Fig. 1. The absence of bands at 1305 and $1174 \mathrm{~cm}^{-1}$ ruled out the existence of Lewis acidic sites in the basic rare-earth oxide $\mathrm{Y}_{2} \mathrm{O}_{3}$.

\subsection{In situ UV-vis DRS of propyl aldehyde condensation over Y/Beta}

In situ UV-vis DRS was further utilized to study the nature of organic intermediates formed during propyl aldehyde conversion. With respect to Y/Beta, a dominant absorption band at $245 \mathrm{~nm}$ with a weak shoulder at $305 \mathrm{~nm}$ appeared at the initial stage of propyl aldehyde conversion (Fig. 6). These bands were due to $\pi \rightarrow \pi^{*}$ and $n \rightarrow \pi^{*}$ transitions of $\mathrm{C}=\mathrm{C}$ and $\mathrm{C}=0$ groups, i.e., 2-methyl-2-pentenal, which were supported by the appearance of bands at 237 and $301 \mathrm{~nm}$ upon 2-methyl-2-pentenal adsorption on Y/Beta at room temperature (Fig. S7). As the propyl aldehyde conversion increased, the concentration of 2-methyl-2-pentenal, reflected by the intensities of the corresponding UV bands (245 and $305 \mathrm{~nm}$ ), gradually increased, indicating the high selectivity toward 2-methyl-2-pentenal over the Y/Beta catalyst, in line with the catalytic results (Fig. 1). In addition, a weak band at about $420 \mathrm{~nm}$ attributed to the $\pi \rightarrow \pi^{*}$ transition of $\mathrm{C}=\mathrm{C}$ groups of aromatics and large coke compounds [53,58], appeared at higher conversion. The unconverted propyl aldehyde adsorbed on $\mathrm{Y}_{2} \mathrm{O}_{3}$ resulted in an absorption band at $235 \mathrm{~nm}$. (Fig. S7). In addition, a band at 355 nm was observed due to the $n \rightarrow \pi^{*}$ transition adsorption of $\mathrm{C}=0$ groups of propyl aldehyde trimers or 2-methyl-2-pentenal. At higher aldehyde conversion, the trimers gradually disappeared and aromatics or coke compounds (band at $416 \mathrm{~nm}$ ) appeared. These observations indicated that the trimers may contribute to the formation of larger aromatics or coke compounds. The relative low intensity of the band at $\sim 420 \mathrm{~nm}$ observed for

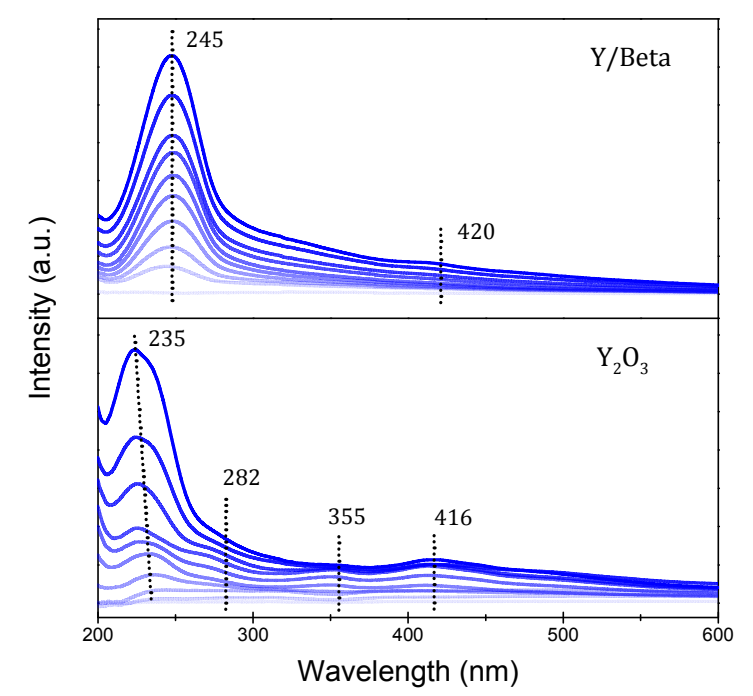

Fig. 6. In situ UV-vis DRS recorded during propyl aldehyde conversion over $\mathrm{Y} /$ Beta and $\mathrm{Y}_{2} \mathrm{O}_{3}$ for TOS of $60 \mathrm{~min}$. Reaction conditions: WHSV = $0.3 / \mathrm{h}, T=573 \mathrm{~K}$. 


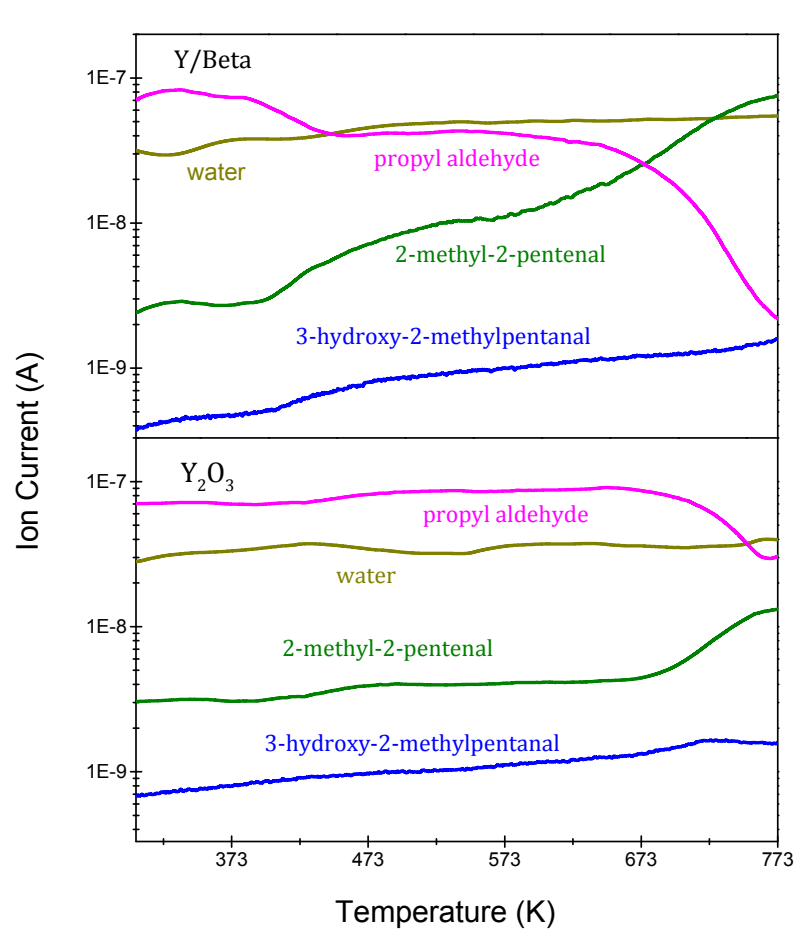

Fig. 7. TPSR profiles of propyl aldehyde conversion over $\mathrm{Y} /$ Beta and $\mathrm{Y}_{2} \mathrm{O}_{3}$ catalysts. Reaction conditions: 0.16 g catalyst, $\mathrm{WHSV}=1.0 / \mathrm{h}$.

$\mathrm{Y} /$ Beta indicated that in contrast to $\mathrm{Y}_{2} \mathrm{O}_{3}$ the coke formation was efficiently suppressed by $\mathrm{Y} /$ Beta.

\subsection{TPSR}

The TPSR profiles of propyl aldehyde conversion over $\mathrm{Y} /$ Beta and $\mathrm{Y}_{2} \mathrm{O}_{3}$ are presented in Fig. 7. For Y/Beta, the propyl aldehyde curve started to decrease at $386 \mathrm{~K}$ and showed a sharp decline at $550 \mathrm{~K}$, indicating that the conversion increased with temperature. The stable curve in the temperature range of 450-550 K revealed a constant propyl aldehyde conversion. Some organic intermediates, i.e. 3-hydroxy-2-methylpentanal and 2-methyl-2-pentenal, exhibited the same trend, and the water curve turned slightly upwards. This indicated the occurrence of dehydration reaction, i.e. converting 3-hydroxy-2methylpentanal to 2-methyl-2-pentenal.

With respect to $\mathrm{Y}_{2} \mathrm{O}_{3}$, the propyl aldehyde curve started to decline at $673 \mathrm{~K}$, which is ca. $200 \mathrm{~K}$ higher compared to the $\mathrm{Y} /$ Beta catalyst. This demonstrates the higher activation energy barrier for propyl aldehyde conversion over $\mathrm{Y}_{2} \mathrm{O}_{3}$ compared to $\mathrm{Y} /$ Beta. In addition, the variation amplitude of the $\mathrm{Y}_{2} \mathrm{O}_{3}$ curve was smaller than that for the Y/Beta catalyst, in accordance with the catalytic performance (Fig. 1). A minimal upwards trend occurred for 3-hydroxy-2-methylpentanal, 2-methyl-2pentenal and water, similar to that observed for $\mathrm{Y} /$ Beta.

\subsection{DFT calculations of aldehyde condensation}

First-principles periodic DFT calculations were performed to understand the structure of yttrium active sites and the re- action pathway for aldehyde self-aldol condensation on Y/Beta. It was proposed that the open Lewis acid sites are more active than the closed ones in Sn-zeolites [59], and therefore, both types of yttrium sites were considered in this work. To simplify the calculations, acetaldehyde was used instead of propyl aldehyde.

The purely siliceous unit cell of BEA zeolite is composed of $64 \mathrm{Si}$ and $128 \mathrm{O}$ atoms with lattice constants optimized to $\mathrm{a}=\mathrm{b}$ $=12.307 \AA, c=26.089 \AA$. As shown in Fig. S8, there are nine crystallographically distinguishable $\mathrm{T}$ sites in this structure and six of them are located in the cross-pore channel. The preferential location of $Y$ species in BEA is identified by partially substituting those six lattice Si atoms with heteroatoms $\mathrm{Y}$ and the T4 site has the lowest energy (Table S3). Figure 8 shows the possible structures of active sites in Y/Beta. The active sites in $\mathrm{Y} /$ Beta-I and $\mathrm{Y} /$ Beta-II are $\mathrm{Y}(\mathrm{OSi})_{3}$ and $\mathrm{Y}(\mathrm{OSi})_{2}(\mathrm{OH})$ (open sites created by hydroxylation of $\mathrm{Y}(\mathrm{OSi})_{3}$ to produce $\mathrm{Y}(\mathrm{OSi})_{m}(\mathrm{OH}) n$ $[m+n=3])$, respectively. The silanol nest is then formed accordingly close to the active yttrium site, which is important to stabilize the open active sites through hydrogen bonding [59]. Acetaldehyde adsorbs on Y/Beta-I and Y/Beta-II through the 0 atom, with adsorption energies of -1.48 and $-1.06 \mathrm{eV}$, respectively (Table S4). The distance between the 0 atom of the carbonyl group and the $\mathrm{Y}$ atom of the active site increases from 2.41 Å on Y/Beta-I to $2.50 \AA ̊$ on Y/Beta-II.

The first aldol condensation step is the keto-enol tautomerization. Due to the absence of Brønsted acid sites, acetaldehyde is deprotonated at the $\alpha$-carbon to generate an enolate ion. DFT-derived enolate formation transition states are involved in the $\alpha-\mathrm{C}-\mathrm{H}$ cleavage and concerted interactions with the $\mathrm{O}$ atom between $\mathrm{Si}$ and Y. Due to the presence of hydroxyl groups at the open sites, the tautomerization of acetaldehyde may involve two different reaction pathways on Y/Beta-II: the concerted interactions with the $\mathrm{O}$ atom adjacent to $\mathrm{Si}$ and the hydroxyl group at the active site. The three possible reaction pathways are denoted as P1, P2 and P3, while the P3 pathway produces

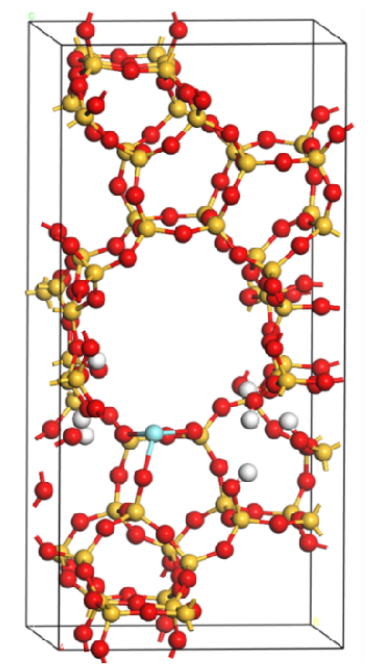

Y/Beta-I

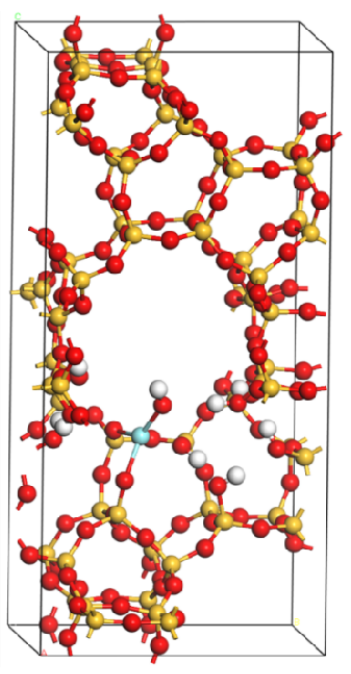

Y/Beta-II
Fig. 8. Optimized structures of Y/Beta. The active sites in Y/Beta-I and $\mathrm{Y} /$ Beta-II are $\mathrm{Y}(\mathrm{OSi})_{3}$ and $\mathrm{Y}(\mathrm{OSi})_{2}(\mathrm{OH})$, respectively. (cyan: $\mathrm{Y}$; yellow: $\mathrm{Si}$; red: 0 ; white: $\mathrm{H}$ ). 
Table 3

Energy barriers $\left(E_{\mathrm{a}}\right)$ and reaction energies $(\Delta E)$ for keto-enol tautomerization of various models.

\begin{tabular}{lccc}
\hline Entry & Model & $E_{\mathrm{a}}(\mathrm{eV})$ & $\Delta E(\mathrm{eV})$ \\
\hline P1 & Y/Beta-I & 1.07 & 0.10 \\
P2 & Y/Beta-II $^{\mathrm{a}}$ & 1.01 & 0.49 \\
P3 & Y/Beta-II $^{\mathrm{b}}$ & 0.82 & 0.38 \\
\hline
\end{tabular}

${ }^{\mathrm{a}}$ Concerted interactions with $\mathrm{O}$; ${ }^{\mathrm{b}}$ Concerted interactions with $\mathrm{OH}$.

the enolate ion and $\mathrm{H}_{2} \mathrm{O}$. Energy barriers $\left(E_{\mathrm{a}}\right)$ and reaction energies $(\Delta E)$ of the keto-enol tautomerization on Y/Beta are presented in Table 3. In the P1 and P2 pathways, the $\mathrm{H}$ atom on the $\alpha$-carbon is abstracted and bound to the 0 atom adjacent to Si. Energy barriers of 1.07 and $1.01 \mathrm{eV}$ are calculated for these two pathways, respectively. In the P3 pathway, the $\mathrm{H}$ atom of acetaldehyde interacts with the hydroxyl group to form $\mathrm{H}_{2} \mathrm{O}$, with the lowest barrier of $0.82 \mathrm{eV}$. The presence of the hydroxyl group significantly lowers the activation energy.

The next step is the nucleophilic addition of the enolate ion to the carbonyl group of the acetaldehyde to form an alkoxide ion. This reaction readily occurs without catalyst in the gas phase with an energy barrier of $0.43 \mathrm{eV}$, which is further lowered using the Y/Beta catalyst. The reaction is exothermic, indicating that the alkoxide ion is more thermodynamically stable than the counterpart in the gas phase. On the selected yttrium models, i.e., Y/Beta-I and Y/Beta-II, the transition state of this reaction is absent, which means that the reaction takes place spontaneously. Once the alkoxide ion is formed, it is easily protonated by the $\mathrm{H}$ atom abstracted in the first step of the aldol dimer generation. Additionally, the $\mathrm{H}$ atoms can be generated from two different sources. In the P1 and P2 pathways, the $\mathrm{H}$-atom can be derived from the $\mathrm{O}$ atom adjacent to $\mathrm{Si}$ atom. While in pathway P3, it originates from water formed in the keto-enol tautomerization. The energy barriers for each reaction are listed in Table 4. Again, the P3 pathway has the lowest barrier, which cannot even be calculated and thus this elementary step also occurs spontaneously.

The last step is the dehydration of the aldol dimer, and the energy barriers for the different reaction pathways are shown in Table 5. The key parameters of the transition states are presented in Table S5. In the gas phase, the energy barrier for the dehydration of the aldol dimer is $2.00 \mathrm{eV}$. For the P1 and P2 pathways, the barriers increase even up to 2.24 and $2.30 \mathrm{eV}$,
Table 5

Energy barriers and reaction energies for aldol dimer dehydration on various models.

\begin{tabular}{lccc}
\hline Entry & Model & $E_{\mathrm{a}}(\mathrm{eV})$ & $\Delta E(\mathrm{eV})$ \\
\hline P1 & Y/Beta-I & 2.24 & 0.35 \\
P2 & Y/Beta-II $^{\mathrm{a}}$ & 2.30 & 0.37 \\
P3 & Y/Beta-II $^{\mathrm{b}}$ & 1.63 & 0.15 \\
Gas phase & & 2.00 & 0.19 \\
\hline
\end{tabular}

a Without hydrogen bond between hydroxyls; ${ }^{\mathrm{b}}$ With hydrogen bond between hydroxyls.

Table 4

Energy barriers and reaction energies of alkoxy anion hydrogenation on various models.

\begin{tabular}{lccc}
\hline Entry & Model & $E_{\mathrm{a}}(\mathrm{eV})$ & $\Delta E(\mathrm{eV})$ \\
\hline P1 & Y/Beta-I & 0.61 & 0.01 \\
P2 & Y/Beta-II $^{\mathrm{a}}$ & 0.33 & -0.31 \\
P3 & Y/Beta-II $^{\mathrm{b}}$ & - & -0.32 \\
\hline
\end{tabular}

${ }^{\mathrm{a}} \mathrm{H}$ from $\mathrm{O}$ adjacent to $\mathrm{Si}$; ${ }^{\mathrm{b}} \mathrm{H}$ from water adsorbed on the active site.

respectively, without the assistance of the hydroxyl group. The aldol dimer stably adsorbs on Y/Beta-I and Y/Beta-II through the $\mathrm{O}$ atom of the hydroxyl and carbonyl group. In the transition state, the $\mathrm{O}$ atom of the hydroxyl group desorbs from the active site and the distance between the 0 atom of the hydroxyl group and the yttrium sites distinctly increases from 2.53 to $3.89 \AA$ A (Fig. 9). The transition state configuration of the dehydration reaction cannot be stabilized by the active sites, which results in an increase in activation energy, excluding the P1 and P2 pathways. In contrast, the transition state of the aldol dimer dehydration is stabilized by $\mathrm{Y}-\mathrm{OH}$ via the hydrogen bond (hydrogen bond distance: $1.46 \AA$ ), and an activation energy of 1.63 $\mathrm{eV}$ calculated (Fig. 9). In comparison with the $\mathrm{P} 2$ reaction pathway without the involvement of $\mathrm{Y}-\mathrm{OH}$, the energy barrier decreases by $0.67 \mathrm{eV}$ (Table 6). The dehydration of the aldol dimer has the highest energy barrier of all reactions, thus is the rate-limiting step, in line with previous studies [60,61]. The energy diagrams for the P1, P2 and P3 reaction pathways are provided in Fig. 10. Although the intermediates formed in the P1 pathway are more stable than those of the other two reaction pathways, the energy barrier for P3 is the lowest and thus P3 is the optimal reaction pathway. The relationship between the energy barrier for the aldol dehydration with the extent of hydroxylation of the active $Y$ sites was further investigated, and

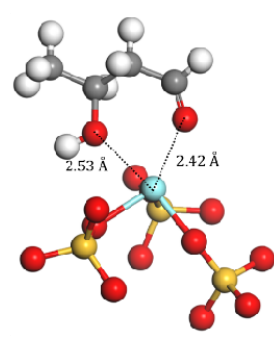

Y/Beta-I

(Initial State)

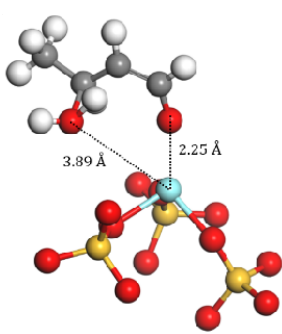

Y/Beta-I

(Transition Szate)

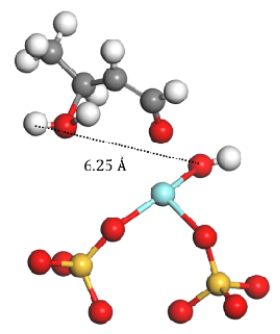

Y/Beta-II

(without the assistance of hydroxyl)

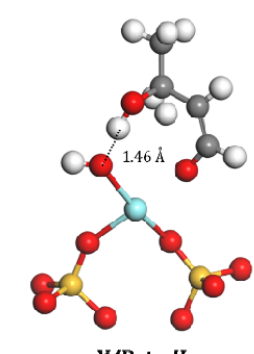

Y/Bela-II

[with the assisance nf hydraxyl]

Fig. 9. Configurations of initial and transition states of aldol dimer dehydration on Y/Beta-I and Y/Beta-II. (cyan: Y; yellow: Si; red: O; gray: C; white: H). 


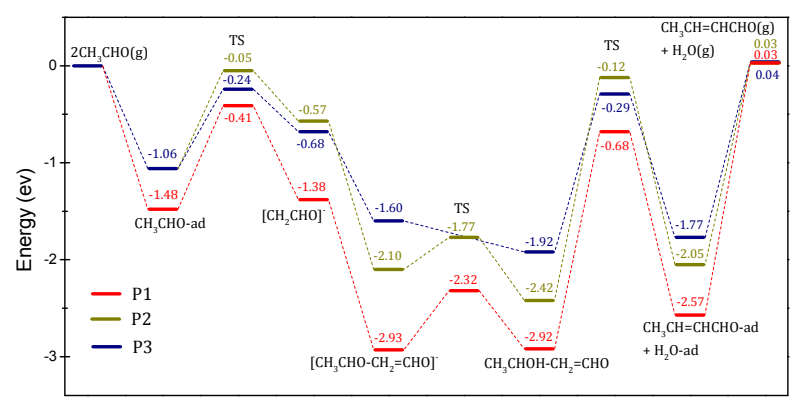

Fig. 10. Energy profiles of acetaldehyde self-aldol condensation over Y/Beta. Three distinct reaction pathways (P1, P2 and P3) are considered.

the lowest energy barrier of $1.45 \mathrm{eV}$ was obtained for the more open $\mathrm{Y}(\mathrm{OSi})(\mathrm{OH})_{2}$ active sites (Fig. S9).

Summarizing the calculation results, we confirmed that the aldol dimer dehydration is the rate-limiting step. The presence of the hydroxyl group on the active site, i.e. in this case the open site, plays an important role in the whole reaction. It reduces the energy barriers for each elementary step, especially for the aldol dehydration. A hydrogen bond is formed between the 0 atom of the hydroxyl group of the active site and the $\mathrm{H}$ atom in the transition state of the aldol dimer, leading to a significant decrease in the activation energy for the aldol dehydration reaction.

\subsection{Mechanistic interpretation of self-aldol condensation over open yttrium sites}

According to DFT calculations, the open yttrium sites are the preferred sites for the self-aldol condensation of aldehydes. Such sites are stabilized by the [Si]Beta zeolite or the $\mathrm{SiO}_{2}$ support, while the zeolite confinement effect further promotes the self-aldol condensation reaction via diffusion control. Herein, the reaction pathway and mechanism of the aldehyde self-aldol condensation at the open yttrium sites stabilized by the [Si]Beta zeolite are well interpreted using the combination of spectroscopic analyses and theoretical calculations, as shown in Scheme 1.

First, the aldehyde adsorbs at the yttrium site, accompanied by the consumption of the $\mathrm{Y}-\mathrm{OH}$ band as demonstrated by in situ DRIFTS (Fig. 5). Thereafter, the aldehyde undergoes an $\alpha-\mathrm{C}-\mathrm{H}$ cleavage and generates a keto-enol structure. The formed $\mathrm{H}$ atom interacts with the hydroxyl group connected to the yttrium center, which is indicated by the lowest energy barrier (Table 3). The enolate ion acts as a nucleophile and adds to another aldehyde molecule, the reaction of which is exothermic and occurs spontaneously. Subsequently, the formed alkoxide ion is protonated by the $\mathrm{H}$ atom from the keto-enol tautomerization step (Table 4) to produce the aldol dimer, as supported by in situ DRIFTS presented in Fig. 5 and TPSR profiles shown in Fig. 7. Finally, the dehydration of the aldol dimer generates the target product 2-methyl-2-pentenal (Figs. 5-7). The transition state of the aldol dimer is stabilized

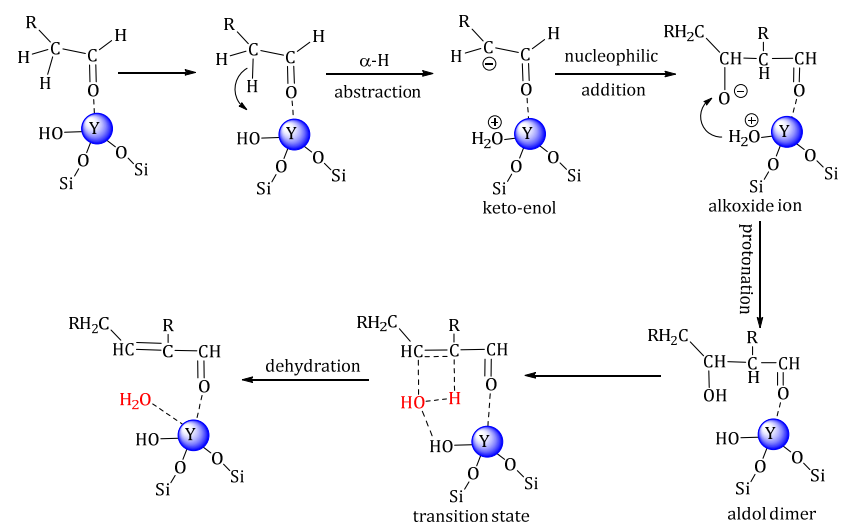

Scheme 1. Reaction pathway and mechanism of the self-aldol condensation of aldehydes over Y/Beta.

through the hydrogen bond from the hydroxyl group at the yttrium ite, which can significantly reduce the energy barrier for the dehydration (Table 5). The energy barrier of the aldol dimer dehydration is the highest of all reactions and therefore the rate-limiting step.

\section{Conclusions}

In summary, the self-aldol condensation of aldehydes was employed as a model reaction to study the catalytic properties of rare-earth cations stabilized by [Si]Beta zeolites and bulk rare-earth metal oxides. It was revealed that Lewis acidic rare-earth cations stabilized by zeolites, particularly Y/Beta, exhibit a satisfactory catalytic performance compared to the basic bulk rare-earth metal oxides. The surface intermediates and products formed during the propyl aldehyde conversion on Y/Beta were investigated via in situ DRIFTS, UV-vis DRS and TPSR. The nature of the active Lewis acidic sites and the reaction pathways over Y/Beta were further explored by DFT calculations. Finally, the reaction mechanism of the aldehyde self-aldol condensation was successfully interpreted via the combination of kinetic and spectroscopic analyses, and theoretical calculations. The aldol dehydration is the rate-limiting step, and the hydroxyl group at the open yttrium site plays an important role in stabilizing the transition state of the aldol dimer and reducing the energy barrier for its dehydration. The catalytic performance of $\mathrm{Y} /$ Beta in the self-aldol condensation of aldehydes was explained in detail, and the different activities of the so-called open and closed yttrium sites were clearly revealed. The catalytic potential of Lewis acidic rare-earth cations stabilized by zeolites was illustrated using the aldehyde self-aldol condensation as a model reaction, which might open up new avenues for these types of unconventional rare-earth catalysts.

\section{References}

[1] J. E. Rekoske, M. A. Barteau, Ind. Eng. Chem. Res., 2011, 50, 41-51.

[2] G. W. Huber, J. N. Chheda, C. J. Barrett, J. A. Dumesic, Science, 2005, 308, 1446-1450.

[3] A. V. Subrahmanyam, S. Thayumanavan, G. W. Huber, ChemSus- 


\section{Graphical Abstract}

Chin. J. Catal., 2021, 42: 595-605 doi: 10.1016/S1872-2067(20)63675-0

Self-aldol condensation of aldehydes over Lewis acidic rare-earth cations stabilized by zeolites

Tingting Yan, Sikai Yao, Weili Dai*, Guangjun Wu, Naijia Guan, Landong Li * Nankai University

Rare-earth cations stabilized by zeolites are robust Lewis acid catalysts for the self-aldol condensation of aldehydes and the hydroxyl groups at the open sites significantly reduce the energy barrier.

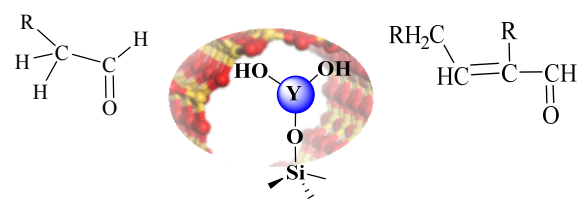

Self-aldol condensation
Chem, 2010, 3, 1158-1161.

[4] H. Li, A. Riisager, S. Saravanamurugan, A. Pandey, R. S. Sangwan, S. Yang, R. Luque, ACS Catal., 2018, 8, 148-187.

[5] Y. Jing, Y. Xin, Y. Guo, X. Liu, Y. Wang, Chin. J. Catal., 2019, 40, 1168-1177.

[6] Z. Ma, X. Ma, Y. Ni, H. Liu, W. Zhu, X. Guo, Z. Liu, Chin. J. Catal., 2018, 39, 1762-1769.

[7] Z. Ma, X. Ma, H. Liu, W. Zhu, X. Guo, Z. Liu, Chin. J. Catal., 2018, 39, 1129-1137.

[8] M. Su, W. Li, Q. Ma, S. Li, T. Yang, X. Dou, Energy Fuels, 2019, 33, 12518-12526.

[9] W. Li, M. Su, T. Zhang, Q. Ma, W. Fan, Fuel, 2019, 237, 1281-1290.

[10] C. J. Barrett, J. N. Chheda, G. W. Huber, J. A. Dumesic, Appl. Catal. B, 2006, 66, 111-118.

[11] Z. D. Young, S. Hanspal, R. J. Davis, ACS Catal., 2016, 6, 3193-3202.

[12] W. Yang, Z. Geng, C. Xu, Q. Guo, D. Dai, X. Yang, J. Phys. Chem. C, 2014, 118, 27920-27924.

[13] T. Moteki, D. W. Flaherty, ACS Catal., 2016, 6, 4170-4183.

[14] X. Liu, R. S. Ding, L. He, Y. M. Liu, Y. Cao, H. Y. He, K. N. Fan, ChemSusChem, 2013, 6, 604-608.

[15] J. D. Lewis, S. Van de Vyver, Y. Román-Leshkov, Angew. Chem. Int. Ed., 2015, 54, 9835-9838.

[16] D. Palagin, V. L. Sushkevich, I. I. Ivanova, J. Phys. Chem. C, 2016, 120, 23566-23575.

[17] I. Cota, E. Ramírez, F. Medina, J. E. Sueiras, G. Layrac, D. Tichit, Appl. Catal. A, 2010, 382, 272-276.

[18] Z. Wang, G. Lu, Y. Guo, Y. Guo, X. Q. Gong, ACS Sustainable Chem. Eng., 2016, 4, 1591-1601.

[19] R. A. L. Baylon, J. Sun, K. J. Martin, P. Venkitasubramanian, Y. Wang, Chem. Commun., 2016, 52, 4975-4978.

[20] A. J. Crisci, H. Dou, T. Prasomsri, Y. Román-Leshikov, ACS Catal., 2014, 4, 4196-4200.

[21] J. A. Bennett, C. M. A. Parlett, M. A. Isaacs, L. J. Durndell, L. Olivi, A. F. Lee, K. Wilson, ChemCatChem, 2017, 9, 1648-1654.

[22] R. W. Snell, B. H. Shanks, ACS Catal., 2013, 3, 783-789.

[23] V. L. Sushkevich, D. Palagin, I. I. Ivanova, ACS Catal, 2015, 5, 4833-4836.

[24] S. Van de Vyver, C. Odermatt, K. Romero, T. Prasomsri, Y. Román-Leshikov, ACS Catal., 2015, 5, 972-977.

[25] R. Bermejo-Deval, M. Orazov, R. Gounder, S. J. Hwang, M. E. Davis, ACS Catal., 2014, 4, 2288-2297.

[26] D. T. Bregante, A. M. Johnson, A. Y. Patel, E. Z. Ayla, M. J. Cordon, B. C. Bukowski, J. Greeley, R. Gounder, D. W. Flaherty, J. Am. Chem. Soc., 2019, 141, 7302-7319.
[27] D. T. Bregante, D. W. Flaherty, J. Am. Chem. Soc., 2017, 139, 6888-6898.

[28] T. Ennaert, J. Van Aelst, J. Dijkmans, R. De Clercq, W. Schutyser, M. Dusselier, D. Verboekend, B. F. Sels, Chem. Soc. Rev., 2016, 45, 584-611.

[29] W. Li, L. Sun, L. Xie, X. Deng, N. Guan, L. Li, Chin. J. Catal., 2019, 40, 1255-1281.

[30] M. Boronat, P. Concepción, A. Corma, M. Renz, S. Valencia, J. Catal., 2005, 234, 111-118.

[31] V. L. Sushkevich, A. Vimont, A. Travert, I. I. Ivanova, J. Phys. Chem. C, 2015, 119, 17633-17639.

[32] M. Boronat, P. Concepción, A. Corma, M. T. Navarro, M. Renz, S. Valencia, Phys. Chem. Chem. Phys., 2009, 11, 2876-2884.

[33] V. L. Sushkevich, I. I. Ivanova, A. V. Yakimov, J. Phys. Chem. C, 2017, 121, 11437-11447.

[34] T. Iida, K. Ohara, Y. Román-Leshkov, T. Wakihara, Phys. Chem. Chem. Phys., 2018, 20, 7914-7919.

[35] W. Dai, S. Zhang, Z. Yu, T. Yan, G. Wu, N. Guan, L. Li, ACS Catal., 2017, 7, 3703-3706.

[36] T. Yan, W. Dai, G. Wu, S. Lang, M. Hunger, N. Guan, L. Li, ACS Catal., 2018, 8, 2760-2773.

[37] T. Yan, L. Yang, W. Dai, C. Wang, G. Wu, N. Guan, M. Hunger, L. Li, J. Catal., 2018, 367, 7-15.

[38] S. Lang, M. Benz, U. Obenaus, R. Himmelmann, M. Scheibe, E. Klemm, J. Weitkamp, M. Hunger, Top. Catal., 2017, 60, 1537-1553.

[39] B. Hammer, L. B. Hansen, J. K. Nørskov, Phys. Rev. B, 1999, 59, 7413-7421.

[40] D. Vanderbilt, Phys. Rev. B, 1990, 41, 7892-7895.

[41] G. Kresse, J. Furthmüller, Phys. Rev. B, 1996, 54, 11169-11186.

[42] J. P. Perdew, K. Burke, M. Ernzerhof, Phys. Rev. Lett, 1996, 77, 3865-3868.

[43] H. J. Monkhorst, J. D. Pack, Phys. Rev. B, 1976, 13, 5188-5192.

[44] J. Wellendorff, K. T. Lundgaard, A. Møgelhøj, V. Petzold, D. D. Landis, J. K. Nørskov, T. Bligaard, K. W. Jacobsen, Phys. Rev. B, 2012, 85, 235149-235171.

[45] G. Henkelman, H. Jónsson, J. Chem. Phys., 1999, 111, 7010-7022.

[46] A. Heyden, A. T. Bell, F. J. Keil, J. Chem. Phys., 2005, 123, 224101-224114.

[47] B. Tang, W. Dai, X. Sun, G. Wu, N. Guan, M. Hunger, L. Li, Green Chem., 2015, 17, 1744-1755.

[48] B. Tang, W. Dai, X. Sun, N. Guan, L. Li, M. Hunger, Green Chem., 2014, 16, 2281-2291.

[49] B. Tang, W. Dai, G. Wu, N. Guan, L. Li, M. Hunger, ACS Catal., 2014, 4, 2801-2810. 
[50] J. P Nogier, Y. Millot, P. P. Man, T. Shishido, M. Che, S. Dzwigaj, J. Phys. Chem. C, 2009, 113, 4885-4889.

[51] S. Dzwigaj, Y. Millot, J. M. Krafft, N. Popovych, P. Kyriienko, J. Phys. Chem. C, 2013, 117, 12552-12559.

[52] D. Yu, W. Dai, G. Wu, N. Guan, L. Li, Chin. J. Catal., 2019, 40, 1375-1384.

[53] A. M. Hernández-Giménez, J. Ruiz-Martínez, B. Puértolas, J. Pérez-Ramírez, P. C. A. Bruijnincx, B. M. Weckhuysen, Top. Catal., 2017, 60, 1522-1536.

[54] P. Müller, S. P. Burt, A. M. Love, W. P. McDermott, P. Wolf, I. Hermans, ACS Catal., 2016, 6, 6823-6832.

[55] A. Gangadharan, M. Shen, T. Sooknoi, D. E. Resasco, R. G. Mallinson,
Appl. Catal. A, 2010, 385, 80-91.

[56] J. P. H. Li, E. M. Kennedy, A. A. Adesina, M. Stockenhuber, J. Catal., 2019, 369, 157-167.

[57] J. Szanyi, J. H. Kwak, R. A. Moline, C. H. F. Peden, J. Phys. Chem. B, 2004, 108, 44, 17050-17058.

[58] W. Dai, M. Dyballa, G. Wu, L. Li, N. Guan, M. Hunger, J. Phys. Chem. C, 2015, 119, 2637-2645.

[59] W. Dai, C. Wang, B. Tang, G. Wu, N. Guan, Z. Xie, M. Hunger, L. Li, ACS Catal., 2016, 6, 2955-2964.

[60] C. R. Ho, S. Zheng, S. Shylesh, A. T. Bell, J. Catal., 2018, 365, 174-183.

[61] S. Wang, K. Goulas, E. Iglesia, J. Catal., 2016, 340, 302-320.

\title{
分子筛稳定的Lewis酸稀土中心在醛自缩合反应中的应用
}

\author{
颜婷婷 ${ }^{\mathrm{a}}$, 姚思凯 ${ }^{\mathrm{a}}$, 戴卫理, ${ }^{\mathrm{a}}$, 武光军 ${ }^{\mathrm{a}}$, 关乃佳 ${ }^{\mathrm{a}, \mathrm{b}}$, 李兰冬 ${ }^{\mathrm{a}, \mathrm{b}, \#}$ \\ a南开大学材料科学与工程学院, 天津 300350 \\ $\mathrm{b}$ 南开大学先进能源材料化学教育部重点实验室, 化学化工协同创新中心, 天津 300071
}

\begin{abstract}
摘要: 羟醛缩合是重要的 $\mathrm{C}-\mathrm{C}$ 键偶联反应, 可以增长碳链, 降低 $\mathrm{O} / \mathrm{C}$ 比, 用于生产很多大宗化学品, 在生物质转化和生物油 升级中广受关注. 本文以丙醛分子自缩合反应作为模型反应, 对比研究了稀土分子篎和稀土氧化物在酫自缩合反应中的 催化性能, 发现稀土分子篎的活性远高于稀土氧化物, 其中Y/Beta活性最佳, 并且具有良好的循环性能. 随后采用程序升温 表面反应(TPSR)、原位漫反射红外光谱(in situ DRIFTS)和原位漫反射紫外光谱(in situ UV-vis DRS)对 $\mathrm{Y} / \mathrm{Beta}$ 和 $\mathrm{Y}_{2} \mathrm{O}_{3}$ 催化丙 醛缩合反应过程进行对比研究. TPSR结果表明, Y/Beta催化剂的反应能垒比 $\mathrm{Y}_{2} \mathrm{O}_{3}$ 低; 通过原位DRIFTS和UV-vis DRS谱结 果发现, $\mathrm{Y} /$ Beta催化剂上Lewis酸位点对丙醛分子具有较强的吸附能力, 利于缩合反应的进行, 而 $\mathrm{Y}_{2} \mathrm{O}_{3}$ 上几乎没有产物的特 征峰, 但出现芳香烃物种的吸收峰, 表明 $\mathrm{Y}_{2} \mathrm{O}_{3}$ 比 $\mathrm{Y} / \mathrm{Beta}$ 催化剂更容易形成积碳物种, 从而造成催化剂失活. 我们还通过密度 泛函理论(DFT)对Y/Beta分子篮的结构及其催化羟醛缩合反应过程进行计算模拟, 揭示了羟醛缩合的主要反应步骤, 即醛 经历烯醇异构化、亲核加成和羟醛二聚体脱水等关键步骤, 其中羟醛二聚体脱水是决速步. 此外, 具有开放结构的 $\mathrm{Y} 中 心$ 的 催化活性比闭合结构的更高, 其羟基可以通过氢键有效稳定羟醛二聚体的过渡态, 从而降低其转化能垒, 并且羟基的数量 越多, 能垒越低. 因此, 具有Lewis酸位点的 $\mathrm{Y}(\mathrm{OSi})(\mathrm{OH})_{2}$ 是羟醛缩合反应的主要活性中心.

综上, [Si]Beta分子篮对活性位点Y-OH的稳定作用, Y-OH是反应的活性位点, 能够显著降低反应的能垒, 而分子笁的 限域作用可以有效控制中间物种的扩散, 从而进一步促进羟醛缩合反应的进行. 醛在反应过程中首先吸附在 $\mathrm{Y}-\mathrm{OH}$ 位点上, 经历 $\alpha-\mathrm{C}-\mathrm{H}$ 键的裂化, 转变成烯醇式结构; 裂化产生的氢原子和 $\mathrm{Y}-\mathrm{OH}$ 中的羟基作用能够大大降低活化能垒; 烯醇式离子 和另一分子醛自发发生亲核加成反应生成醇盐离子, 生成的醇盐离子与烯醇异构化反应中裂化的氢原子发生质子化反应, 从而得到羟醛二聚体; 最后, 羟醛二聚体吸附在 $\mathrm{Y}-\mathrm{OH}$ 上, 通过氢键稳定过渡态, 降低了活化能垒, 诱发脱水反应生成最终 产物.
\end{abstract}

关键词: 羟醛自缩合反应; 醛; 稀土中心; 分子篎; Lewis酸

收稿日期: 2020-05-17. 接受日期: 2020-06-28. 上网日期: 2020-09-05.

*通讯联系人. 电话/传真: (022)85358536; 电子信箱: weilidai@nankai.edu.cn

\#通讯联系人. 电话/传真: (022)23500341; 电子信箱: lild@nankai.edu.cn

基金来源：国家自然科学基金(21872072); 天津市自然科学基金(18JCZDJC37400, 18JCJQJC47400); 中国石化(419040).

本文的电子版全文由Elsevier出版社在ScienceDirect上出版(http://www.sciencedirect.com/science/journal/18722067). 